\title{
Day of Diversity
}

\section{Extending the Dialogue, Encouraging the Action}

\author{
SARAH PARK DAHLEN AND LESSA KANANI'OPUA PELLYO-LOZADA
}

$\mathrm{I}$ n January, we participated in ALSC and the Children's Book Council's ALA 2015 Midwinter preconference, Day of Diversity: Dialogue and Action in Children's Literature and Programming in Chicago. ${ }^{1}$ The goal of the event was to bring together leaders in children's literature and literacy to discuss strategies for ensuring that all children have access to diverse literature and library programming.

ALSC has been increasing its attention to issues of diversity, particularly with the release of Dr. Jamie Campbell Naidoo's white paper, "The Importance of Diversity in Library Programs and Material Collections for Children."2 Naidoo highlights the importance of libraries as "trusted spaces that welcome children to explore, discover, and connect to the larger world ... helping them develop understanding and respect for other people from diverse cultural and linguistic backgrounds." 3

As one of the major organizers of the Day of Diversity, Naidoo put his work into action for all of the invited participants. We are thankful and honored to be included among the seventy or so attendees who have been working toward equity in children's literature and library programming for years, and in many cases, decades, acting as inspiration and mentors to our own work in diversity.

The day included a keynote address, three panels with two related breakout sessions, and a lunch with lightning talks. Our invited role in the day was to facilitate breakout sessionsSarah's task was to strategize with her group on how to increase diversity in print and digital materials and Lessa's task with her group was to identify partners to attract diverse people and families to publishing and the library. These tasks, and our discussions throughout the day, were guided by several key questions such as the following:

- How do we create mirrors and windows for our children in the books and media around us? Mirrors to our/their own experiences, and windows to experiences not our own?
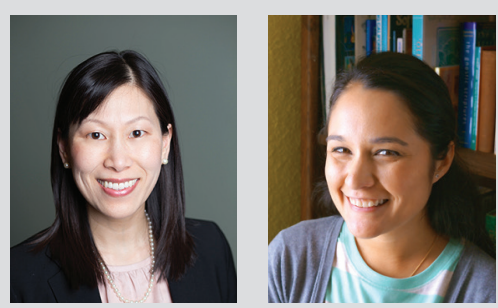

Sarah Park Dahlen is an Assistant Professor in the Master of Library and Information Science Program at St. Catherine University in St. Paul, MN. She teaches courses on children's and young adult materials, children's and young adult library services, storytelling, and social justice, and serves on the University of Minnesota Kerlan Friends Board and the WNDB Walter Award Committee. She co-edited Diversity in Youth Literature: Opening Doors Through Reading (ALA Editions, 2012) with Dr. Jamie Naidoo. Her next project examines race in the Harry Potter series. Reach her at sarahpark.com. Lessa Kanani'opua Pelayo-Lozada is a Librarian at the Rancho Cucamonga (CA) Public Library. She currently serves the Asian Pacific American Librarians Association as Vice President/President-Elect and is the past chair of the "Talk Story: Sharing Stories, Sharing Culture" APA/AIAN family literacy program and serves as ALA Councilor-at-Large. She is a current member of the WNDB Walter Award Committee and past APALA Young Adult Literature Awards Chair. 


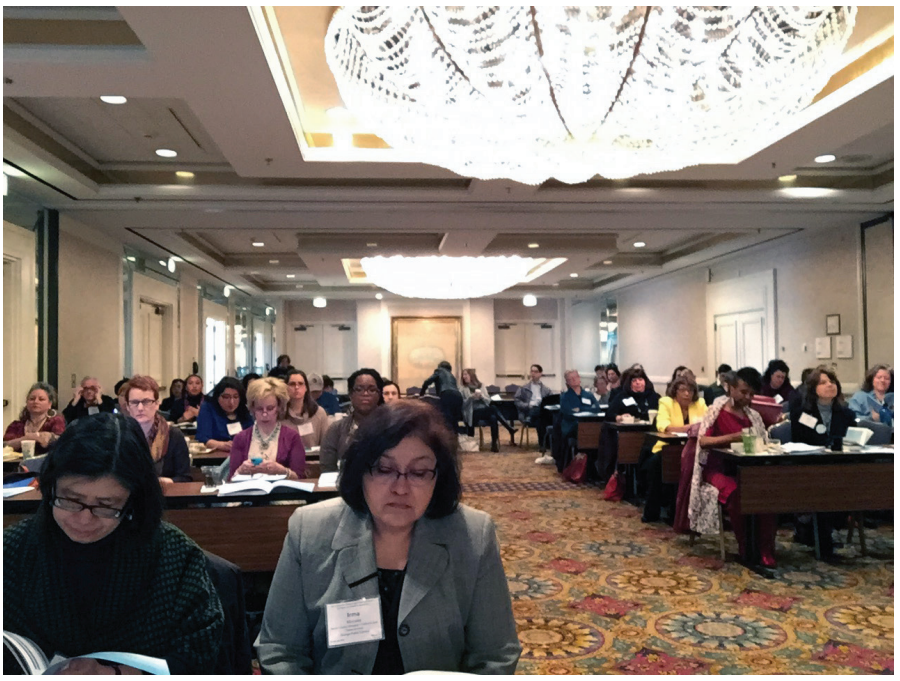

Photo of the Day of Diversity room from Sarah and Lessa's seats.

- How do we help close the growing literacy gaps?

- How can we work together with publishers?

- How do we encourage writers of color to tell their stories?

To frame the larger context for the day, we started with a keynote address by Dr. Camila Alire (Dean Emerita of the University of New Mexico and Colorado State University and past president of ALA, ACRL, and REFORMA). Alire related some depressing, but not surprising, realities, such as the fact that children's books actually became less diverse between 2002 and 2013, according to statistics ${ }^{4}$ compiled by the Cooperative Children's Book Center (CCBC) at the University of Wisconsin-Madison. This decline occurred while minority populations in the U.S. increased 28.8 percent during nearly the same time period, a trend that will continue until minority populations eclipse the majority population in $2050 .^{5}$

This raises the perennial question: Why are there still so few books about such a huge and growing portion of the population? We need diverse materials that reflect our diverse world. If young people don't have materials that reflect them visually and contextually, they may be less engaged and less likely to read, resulting in lower literacy and high school graduation rates. The cause and effect is not only on the children missing in these books, however, since children who are unable to read about experiences other than their own will not learn how to be empathetic and treat each other as equal lives that matter.

Continuing down the path of education and information, the mythbusters panel following the keynote debunked common false beliefs such as, "Diverse books don't sell"-they do, said agent Adriana Dominguez, agent at Full Circle Literary-or, "We're living in a post-racial society,"-we're clearly not, said Kathleen T. Horning, director of the CCBC. Horning also cited CCBC statistics and the \#WeNeedDiverseBooks campaign to point out that race matters in both its presence and absence.

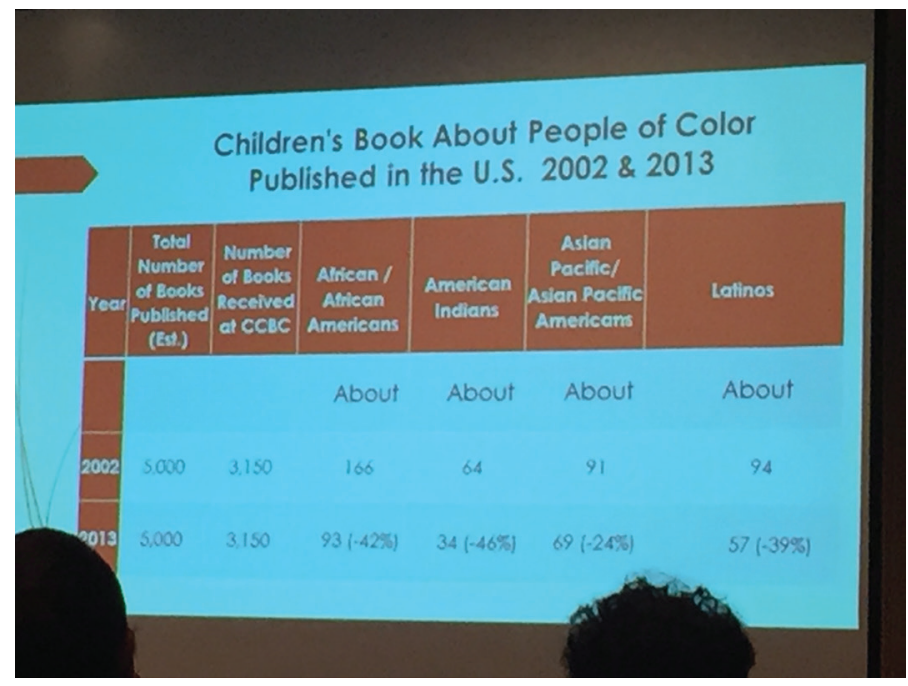

CCBC statistics on Dr. Alire's presentation slide.

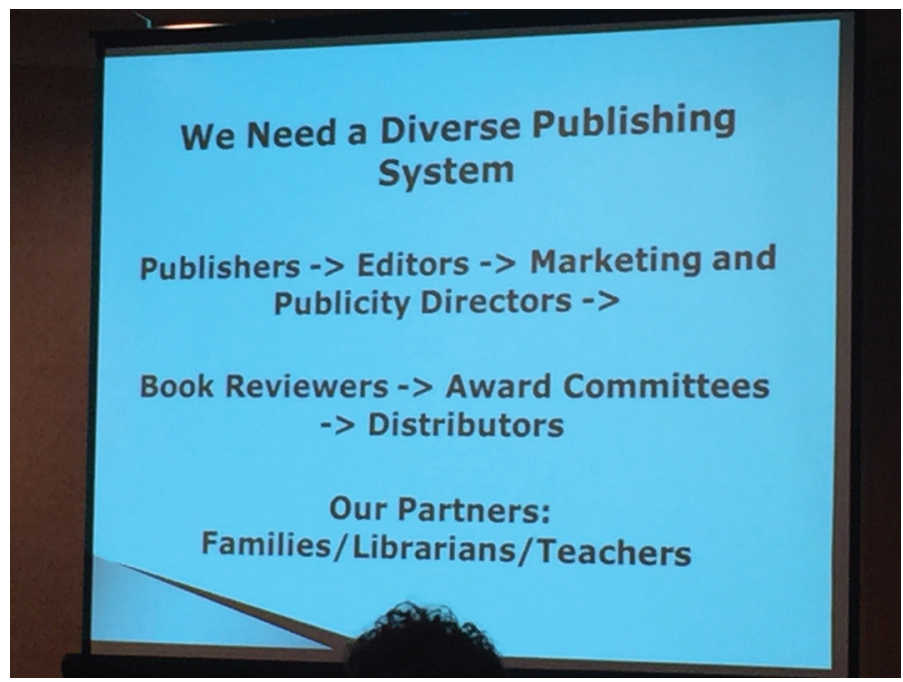

Pat Mora's proposed diverse publishing system.

During the first breakout session, which continued ideas from the mythbusters panel, participants brainstormed ways to increase diversity in youth materials and strategized how to get those materials into the hands of young people. Participants shared ideas on organizing out-of-the-box events, such as cooking classes and summer camps. ${ }^{6}$ Wade Hudson, president of Just Us Books, discussed his success working with churches, community centers, and sororities, emphasizing the importance of getting out into the community, in locations where people actually gather.

After a packed morning, lunch provided the opportunity for three authors and an editorial director to deliver moving talks during which they shared very personal and often painful experiences that expose some of the micro-and macro-aggressions that non-majority people experience in publishing.

For example, Ellen C. Oh, author and co-founder of We Need Diverse Books, shared her childhood experiences with schoolyard racism. After talking about the absence of diverse stories in her youth, she said she writes for her Korean-American 


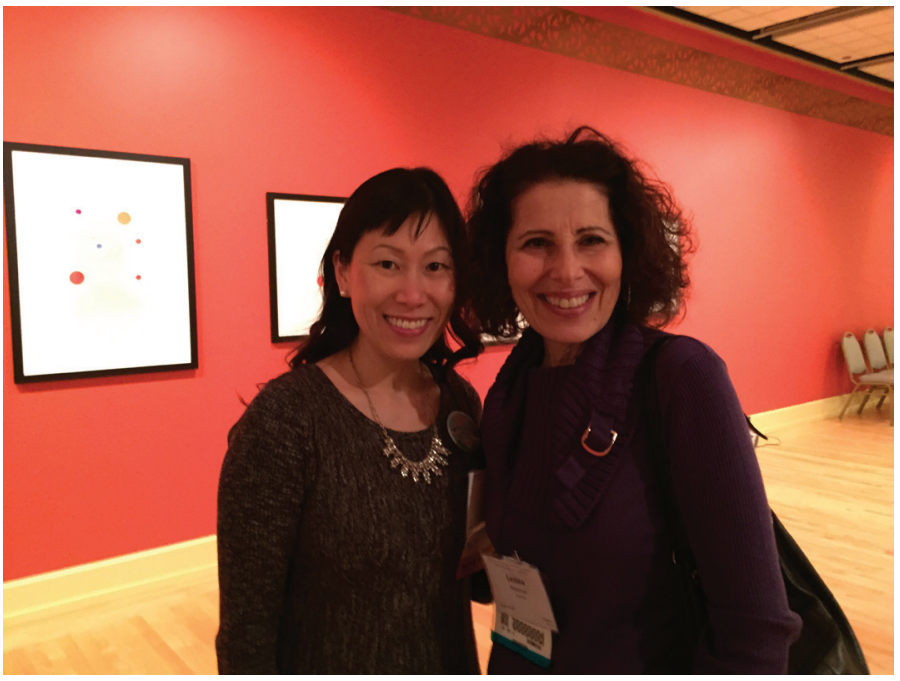

Sarah Park Dahlen and Lesléa Newman (author of Heather Has Two Mommies and October Mourning: A Song for Matthew Shepard), at the reception.

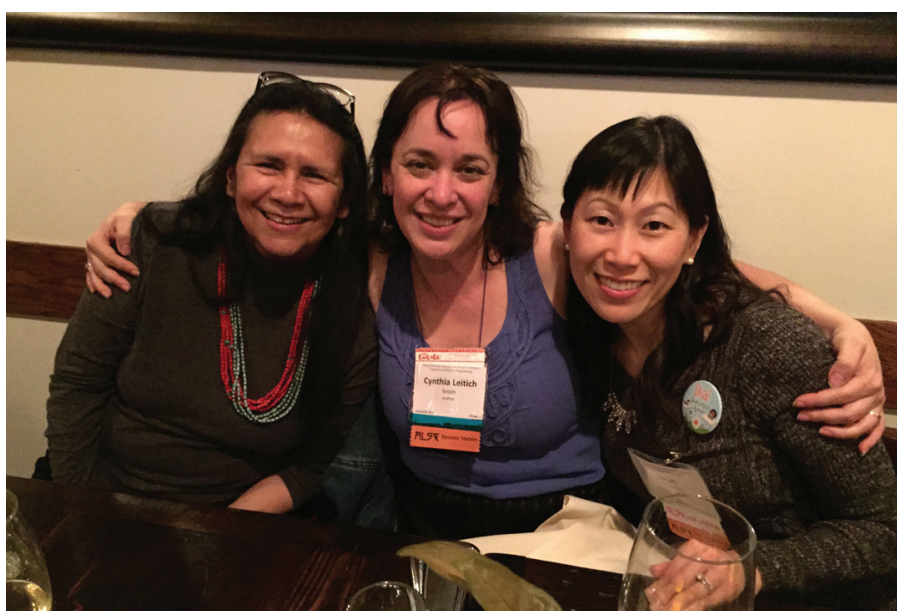

Debbie Reese (scholar), Cynthia Leitich Smith (author of Jingle Dancer, Rain Is Not My Indian Name, and the Feral series), and Sarah Park Dahlen, at a We Need Diverse Books dinner after the Day of Diversity.

daughters because "[she] wanted them to know that they could grow up to be smart, powerful women who could dare to dream to be whatever they want ... to find stories that they could embrace and that would help mold them."

Dial Books for Young Readers Editorial Director Namrata Tripathi talked about how people make assumptions regarding her role in publishing due to her ethnic background, how people make her feel as though she should apologize that they don't know how to pronounce her name, and how she learned to advocate for herself in the same way she advocates for diverse literature. She ended her talk beautifully_- Instead of saying goodbye, I'm saying hello, my name is Namrata Tripathi, and I'm very pleased to meet you."

The second panel, "Literacy Programming: Forming Partnerships and Sharing Resources," was moderated by the Center for the Study of Multicultural Children's Literature's Dr. Claudette McLinn. Hard-hitting and unapologetic, author

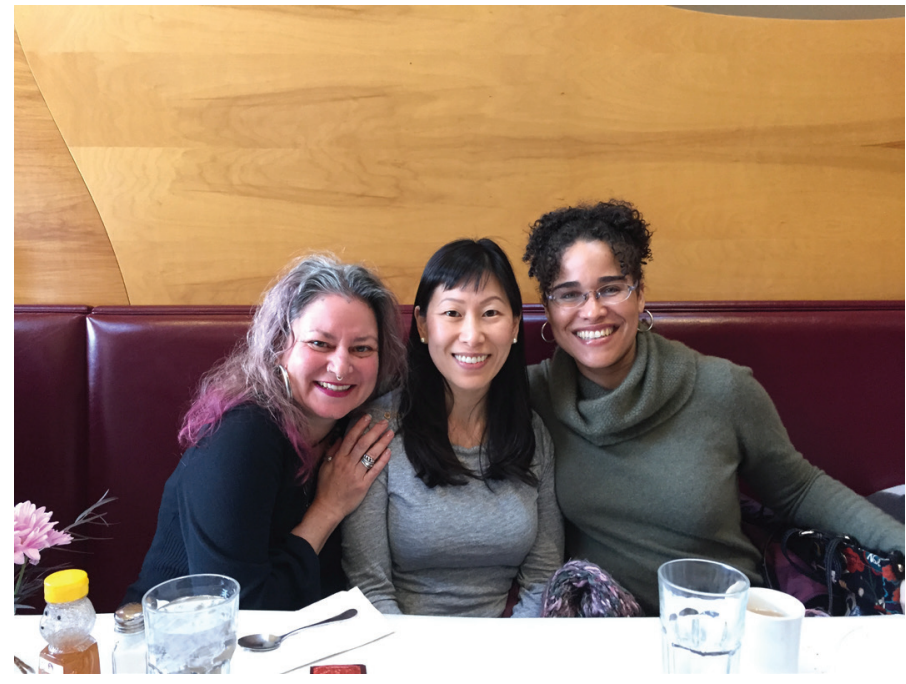

Maya Christina Gonzalez (author, illustrator, educator, and activist), Sarah Park Dahlen, and Zetta Elliott (author, educator, and activist), the morning after Day of Diversity

Pat Mora, founder of the successful Día initiative, suggested a new model of publishing that would make the publishing process more transparent and redistribute power among those involved. ${ }^{7}$ Teaching Tolerance Director Maureen Costello warned us not to assume that educators-mostly white females over the age of 50 who have been teaching for more than fifteen years-know how to match books with children or even talk about diverse topics.

The same can be said for librarians. We have no illusions that education and library science programs have sufficiently prepared educators to teach diverse topics; today, hopefully, that is changing. For example, Sarah teaches a course called Social Justice in Children's/YA Literature at St. Catherine University, and many of her colleagues teach similar courses in their LIS, English, and education programs. Sadly, the reality is that some librarians and teachers complain that they can't get their readers to read diverse books; in response to these kinds of comments, librarian and blogger Amy Koester writes, "I feel very strongly that if the excellent diverse books in your collection do not circulate, you are not doing your job of getting great books into the hands of readers."

During the second breakout session, participants discussed the role of the librarian in creating partnerships and programming to help patrons build global citizenship, compassion, and empathy, as well as how to empower those librarians to care for the needs of their community and seek out resources. One important reminder from Lessa's group included the knowledge that review journals, which librarians rely heavily upon, don't include every published book. Books by smaller, diverse publishers, such as Cinco Punto Press, and those by self-published authors are less likely to be reviewed by publications that require a review fee or review only traditionally published works. Also, librarians and educators should read Malinda Lo's article series, "Perceptions of Diversity in Book Reviews," weeks after Day of Diversity, which reveals precisely why book reviews are not always fully reliable sources when evaluating 
books that contain diverse content. For example, Lo writes, "I don't think it's a stretch to hypothesize that the majority of book reviewers are white, and when they encounter a character with an intersectional minority identity, they must make an extra effort to understand them. What I see . . . however, is majority reviewers deciding not to make that extra effort; instead, they are demanding that the books be simplified for readers who are not minorities." ${ }^{10}$ To help rectify this issue, Lee \& Low has partnered with Sarah to conduct a Diversity Baseline Survey to examine where we are in terms of our publisher and reviewing journal employee demographics, so we can figure out where we would like to be. ${ }^{11}$

Our final panel concluded with a call to action by Satia Orange, former director of the ALA Office for Literacy \& Outreach Services. We were asked what we were going to do about the things we learned and discussed that day. How are we going to effect change in one week, six months, twelve months? Participants were invited to share their hopes and action steps for the future, with a consensus that while many of us are suffering advocacy fatigue, working together at the Day of Diversity renewed our spirits, pushing us toward each other to create the change we want to see.

Many agreed that one of the best parts of the event was being in the same room as like-minded colleagues-those we know in person and those we've read and respected through social media, creating a human connection beyond text.

Because lives matter. Because we inspire each other to do great things. Because our young people need us to do these things.

These connections lead to the dialogue that needs to happen on a regular basis, and not just isolated to one day or one month or only on Twitter and Tumblr. We need to have the difficult conversations with each other, with our communities, and with the publishing, library, and education worlds on an ongoing basis.

To help us have these conversations and discussions, the first half of the day served as a Diversity 101 for the benefit of those who weren't already engaged in conversations surrounding problems of equity, diversity, and inclusion. As author and educator Zetta Elliott wrote, "The 100 invited guests shared a commitment to diversity in an abstract sense, but at times it felt like the discussions were only scratching the surface" 12 to some participants who have been engaged in the dialogue and work surrounding these topics for a while.

For those participants, the Diversity 101 section acted as a unity builder to look around the room and see nodding heads; not just in affirmation of the facts being brought forth, but also in a deep knowledge of our long and ongoing fight for equity. Now, hopefully, we are all on the same page and there is no excuse for ignoring issues of power and growth in our minority communities, especially as we strive to continue the conversation and expand on what we were unable to discuss.
Interestingly, because the Day was already quite full, explicit discussions of power, oppression, dominance, and privilege seemed absent. As well, participants respected the communications norms suggestions that, for example, asked us to "call each other in instead of calling each other out." There was a politeness that was encouraged and for the most part, observed. We don't feel that anyone should have been rude or made to feel out of place, but as Laura Thatcher Ulrich, history professor at Harvard University, said, "Well-behaved women seldom make history" and as Frederick Douglass said, "Power concedes nothing without a demand. It never did and never will." Given that we've been making demands for years, now is the time to make those demands with a "roar that can't be ignored." 13

Panel moderator and Language and Literacy Professor Violet Harris of the University of Illinois and others pointed out that we've been having this same conversation and making these same demands not for just a year or a few years but for decades (on her blog, Edith Campbell wrote, "Violet Harris reminded us, this fight has been going on since 1847 with the publication of The Anti-Slavery Alphabet," ${ }^{14}$ and Debbie Reese pointed out that as early as 1927, "Native parents in Chicago wrote letters, objecting to the ways Native peoples were portrayed in textbooks." $)^{15}$ Mora pointed out that the system needs to change; Alire showed us that the publishing numbers are getting worse.
The Day of Diversity ended on an intense note; when Orange exhorted us to put our words into action and DO SOMETHING because \#BlackLivesMatter; because we are ingratiated into a system that is not interested in letting diverse voices speak; because, whether intentional or not, the system wants to keep us illiterate, voiceless, and powerless; because keeping our stories out of circulation is one way to do that-that the something that we can do now is to band together, to make our voices heard and stop policing each other, so that we can change the world into OUR world, where all of our voices participate loudly, clearly, and equitably.

As we went back to our hotels and homes, many participants took time to digest the day and reflect upon Orange's call to action, and the conversations that took place through their own writing. Several colleagues such as Elliott, Reese, and Campbell eloquently lent their own views on the event and added a number of perspectives to how we can move forward. We highly recommend you read their blog posts, as well as the comment sections (links are in the references of this article). We can all add to the dialogue by moving to action, and so can you.

Among the many ideas suggested by our colleagues, we recommend starting with these easy-to-implement actions:

1. Buy diverse books (for your library, for your school, for the children in your life) 
2. Promote diverse books in traditional and creative ways, and not only during a "diversity" week or month, but all year round.

3. Read and support award-winning books (including awards given by diverse groups such as the ethnic caucuses), and also find other books not included on award lists.

4. Make your voice heard whether it be through a letter writing campaign (Sarah has a great one available on her website), commenting on blogs, or having one on one conversations with anyone willing (and unwilling) to listen.

The Day of Diversity is not The End. The Day of Diversity was also not The Beginning. It is a point along the continuumhopefully a tipping point that, as the We Need Diverse Books campaign has pointed out, will encourage us "to raise our voices into a roar that can't be ignored." A roar of today. Of now. Of tomorrow.

The industry-indeed, the world—can't ignore the fact that the number of multicultural books has not increased in the past twenty years. It can't ignore the fact that our society continues to diversify. It can't ignore the fact that publishing does not. It can't ignore the fact that there are very talented, diverse authors and illustrators who make wonderful and amazing children's books. It can't ignore the fact that a lack of diverse books hurts ALL children. It can't ignore the fact that we need to have these conversations, that we need to address these issues, and we need to talk them out and DO SOMETHING to CHANGE the system. And we can't do it alone. None of us can do the work alone, as Debbie Reese so rightfully reminded us. None of us is a single representative. None of us can be a single voice. We all have a stake, and we should all work to dismantle racism and promote equity in children's literature and librarianship. Many of us-including those not mentioned here-are already at work, and now, more than ever, we need to STEP IT UP. Won't you join us?

\section{References}

1. Association for Library Service to Children, "Day of Diversity,” accessed April 24, 2015, dia.ala.org/ dayofdiversity.

2. Jamie Campbell Naidoo, "The Importance of Diversity in Library Programs and Material Collections for Children," accessed 24 April 2015, www.ala.org/alsc/sites/ala.org .alsc/files/content/ALSCwhitepaper_importance\%20 of\%20diversity_with\%20graphics_FINAL.pdf.

3. Ibid.

4. Cooperative Children's Book Center at the University of Wisconsin-Madison, "Children's Books By and About People of Color,” accessed May 22, 2015, https://ccbc .education.wisc.edu/books/pcstats.asp.

5. Camila Alire, "From Broken Yolks to Party Folks: The Importance of Libraries and Literacy in Keeping Diversity Alive for Our Children.” Day of Diversity: Dialogue and Action.

6. La Casa Azul Bookstore, accessed April 25, 2015, www .lacasaazulbookstore.com.

7. See Zetta Elliott's article, "Black Authors and Self Publishing” in School Library Journal (March 16, 2015) for another perspective on the systemic issues with children's book publishing, see www.slj.com/2015/03/diversity/ black-authors-and-self-publishing.

8. Amy Koester, The Show Me Librarian, "Selection Is Privilege,” accessed April 24, 2015, http://showme librarian.blogspot.com/2015/02/selection-is-privilege .html.

9. Malinda Lo, Diversity in YA: Puttin' a Little Diversity in YA Since 2011, "Perceptions of Diversity in Book Reviews," accessed April 24, 2015, www.diversityinya.com/2015/02/ perceptions-of-diversity-in-book-reviews.

10. Ibid.

11. Jason Low, “The Diversity Baseline Survey,” Lee \& Low, accessed May 22, 2015, www.leeandlow.com/about-us/ the-diversity-baseline-survey.

12. Zetta Elliott, Zetta Elliott: Author Educator, "Power Surge,” accessed April 24, 2015, www.zettaelliott.com/power -surge/.

13. We Need Diverse Books Campaign, We Need Diverse Books Official Campaign Tumblr, accessed April 24, 2015, http:// weneeddiversebooks.tumblr.com/post/83943947418/we -need-diverse-books-campaign.

14. Edith Campbell, Crazy QuiltEdi, “Rap It Up,” accessed April 24, 2015, https://campbele.wordpress.com/2015/02/02/ rap-it-up.

15. Debbie Reese, American Indians in Children's Literature, "Do Something Dramatic! AICL's Recap of ALA's Day of Diversity," accessed April 24, 2015, http:/ / americanindiansinchildrensliterature.blogspot.com/ 2015/02/do-something-dramatic-aicls-recap-of.html. 